\title{
Predictors of periodontal and caries related perinatal oral healthcare, Investigation of Dentists' practices: a cross- sectional study
}

\author{
Muhammad Qasim Javed ${ }^{\text {Corresp., } 1}$, Usman Anwer Bhatti ${ }^{2}{ }$ Arham Riaz $^{3}$, Farooq Ahmad Chaudhary ${ }^{4}$ \\ 1 Department of Conservative Dental Sciences and Endodontics, College of Dentistry, PO Box 6700, 51452, Qassim University, Buraydah, Qassim, Saudi \\ Arabia \\ 2 Department of Operative Dentistry, College of Dentistry, Riphah International University, Islamabad, Pakistan \\ 3 Community Dentistry, Academy of Continuing Health Education and Research, Islamabad, Pakistan \\ 4 School of Dentistry, Shaheed Zulfiqar Ali Bhutto Medical University., Islamabad, Pakistan \\ Corresponding Author: Muhammad Qasim Javed \\ Email address: M.Anayat@qu.edu.sa
}

Background: The objectives of the study were to assess the knowledge, attitude, and practice of dentists towards providing oral health care to pregnant women and to identify barriers and predictors of periodontal and caries related perinatal oral healthcare practices. Methods: A cross-sectional analytical survey was conducted on dentist by using a random sampling technique, and a pre-validated questionnaire was delivered to 350 dentists from May 2018 to October 2018. Data were analyzed by utilizing SPSS software. Frequencies and percentages were recorded for descriptive variables. Binary logistic regression was used to analyze the probability of predicting group membership to the dependent variable using different independent variables determined from contingency tables. Results: Overall response rate was $41 \%$. The mean knowledge score of respondents was $15.86+3.34$. The lowest correct responses were noted in the questions related to periodontal health. It was found that the advice to delay dental visits until after pregnancy was 8 times more likely to be observed among dentists who lacked the knowledge of importance of oral health during pregnancy $(P=0.04, O R=8.75)$. Dentists were more likely to consult obstetricians regarding dental procedures when they fear a risk of labor in the dental practice $(P<0.05,0 R=3.72)$.Dentists who had the knowledge of periodontal disease association with preterm delivery were about 4 times more likely to treat periodontal disease during pregnancy $(P=0.01, O R=3.95)$. Dentists knowing the association between maternal oral health and childhood decay were more likely to counsel pregnant patients regarding caries prevention $(P>0.05, O R=3.75)$. Conclusions: Collectively the results indicated few gaps in knowledge among some dentists and a need to improve existing attitudes towards perinatal oral health. Dentists failing to recognize the importance of perinatal oral health are more likely to be hesitant in treating pregnant PeerJ reviewing PDF | (2021:01:57360:1:0:NEW 15 Jul 2021) 
patients. Failing to recognize the link between periodontal disease and obstetric complications increases the possibility of hesitance to counsel pregnant patients regarding the same. The appreciation of the evidence for poor perinatal oral health and risk of early childhood caries increases the likelihood of counseling by dentists on caries prevention. 
1 Predictors of periodontal and caries related perinatal oral healthcare, Investigation of

2 Dentists' practices: a cross-sectional study

3 Muhammad Qasim Javed ${ }^{1}$, Usman Anwer Bhatti ${ }^{2}$, Arham Riaz 3 , Farooq Ahmad Chaudhary ${ }^{4}$

4

$5{ }^{1}$ Assistant Professor, Department of Conservative Dental Sciences and Endodontics, College of 6 Dentistry, Qassim University, Buraydah, Qassim,Saudi Arabia.

72 Assistant Professor, Department of Operative Dentistry, College of Dentistry, Riphah

8 International University, Islamabad, Pakistan

$9{ }^{3}$ Lecturer, Community Dentistry, Academy of Continuing Health Education and Research, 10 Islamabad, Pakistan

$11{ }^{4}$ Farooq Ahmad Chaudhary, School of Dentistry, Shaheed Zulfiqar Ali Bhutto Medical 12 University, Islamabad, Pakistan.

13

14 Corresponding Author:

15 Muhammad Qasim Javed

16 Assistant Professor, College of Dentistry, Qassim University, Buraydah, PO Box 6700, 51452,

17 Qassim, Saudi Arabia

18 Email address: M.Anayat@qu.edu.sa 


\section{Abstract}

25 Background: The objectives of the study were to assess the knowledge, attitude, and practice of dentists towards providing oral health care to pregnant women and to identify barriers and 27 predictors of periodontal and caries related perinatal oral healthcare practices. Methods: A cross-sectional analytical survey was conducted on dentist by using a random sampling technique, and a pre-validated questionnaire was delivered to 350 dentists from May 2018 to October 2018. Data were analyzed by utilizing SPSS software. Frequencies and percentages were recorded for descriptive variables. Binary logistic regression was used to analyze the probability of predicting group membership to the dependent variable using different independent variables determined from contingency tables.

Results: Overall response rate was $41 \%$. The mean knowledge score of respondents was 15.86+3.34. The lowest correct responses were noted in the questions related to periodontal health. It was found that the advice to delay dental visits until after pregnancy was 8 times more likely to be observed among dentists who lacked the knowledge of importance of oral health during pregnancy $(\mathrm{P}=0.04, \mathrm{OR}=8.75)$. Dentists were more likely to consult obstetricians regarding dental procedures when they fear a risk of labor in the dental practice $(\mathrm{P}<0.05, \mathrm{OR}=3.72)$. Dentists who had the knowledge of periodontal disease association with

41 preterm delivery were about 4 times more likely to treat periodontal disease during pregnancy $42(\mathrm{P}=0.01, \mathrm{OR}=3.95)$. Dentists knowing the association between maternal oral health and childhood 43 decay were more likely to counsel pregnant patients regarding caries prevention $44(\mathrm{P}>0.05, \mathrm{OR}=3.75)$.

45 Conclusions: Collectively the results indicated few gaps in knowledge among some dentists and 46 a need to improve existing attitudes towards perinatal oral health. Dentists failing to recognize 
47 the importance of perinatal oral health are more likely to be hesitant in treating pregnant patients.

48 Failing to recognize the link between periodontal disease and obstetric complications increases

49 the possibility of hesitance to counsel pregnant patients regarding the same. The appreciation of

50 the evidence for poor perinatal oral health and risk of early childhood caries increases the

51 likelihood of counseling by dentists on caries prevention.

\section{Introduction}

53 Pregnancy is a physiologically challenging condition with numerous hormonal changes

54 contributing to an increased risk of oral diseases. ${ }^{1,2}$ The two oral diseases responsible for most

55 oral health problems in pregnant women are caries and periodontal diseases. ${ }^{1,2,3}$ In a developing

56 country like Pakistan, moderate to severe oral disease burden has been reported concerning

57 pregnant women. ${ }^{3}$ Preterm low birth weight (LBW), stillbirth, neonatal, and prenatal death are

58 some of the serious implications of inadequate periodontal health of pregnant women. ${ }^{4,5,6} \mathrm{LBW}$

59 is a serious health care problem in Pakistan where the reported incidence of LBW is $37 \% .^{7}$

60 Moreover, LBW can contribute to early childhood caries. ${ }^{8}$ Accordingly, WHO noted preterm

61 birth (PB) (delivery at $<37$ weeks gestation ) and low birth weight as the two most common

62 reasons for neonatal mortality. ${ }^{9}$ Current evidence base suggests that PB usually leads to LBW

63 (baby weight $<2.5 \mathrm{~kg}$ ). ${ }^{10,11}$ Boggess and Edelstein attributed almost $18 \%$ of the PB and LBW to

64 periodontal disease. ${ }^{12}$ This might be the result of increased levels of inflammatory mediators and

65 cytokines (IL-8, TNF) released during periodontal inflammation. Furthermore, the mediators and

66 cytokines may enhance prostaglandin production resulting in early labor. ${ }^{13}$

67 The oral health of the expectant mother has been indicated as a significant predictor of children's

68 oral health and mothers are usually considered the primary source of cariogenic bacteria

69 transmission to children. ${ }^{14}$ Researchers have reported similarities (genotypic and phenotypic) 
70 among the streptococcus mutans (SM) bacteria found in the oral cavity of the child and mother. ${ }^{15}$

71 Considering this, children with high SM count during early life might have it transmitted from

72 the saliva of a mother with an active carious lesion, particularly during certain feeding

73 practices. ${ }^{16,17}$ Moreover, studies show that maternal oral hygiene practices and diet can also

74 influence this risk. ${ }^{18}$ Hence maintaining the oral health of pregnant women is not only important

75 for minimizing the risk of obstetric complications but also for the future oral health of both

76 mother and infant. ${ }^{19}$

77 The susceptibility of pregnant women to problems pertaining to oral health is further increased as 78 only half of these women are reported to seek oral health care. ${ }^{20}$ Considering that most dental 79 care is safe during pregnancy, such a low number of women seeking care is alarming. ${ }^{19}$ Lack of 80 care can lead to an escalation of pre-existing dental problems with the literature reporting a high 81 prevalence of dental pain among pregnant women. ${ }^{2}$

82 There can be different barriers to seeking oral health care among pregnant women, like 83 economics and concern for fetal health. However, in addition to patient-related factors, there is a 84 matter of dentists' perception which acts as a barrier in providing oral health care to pregnant 85 women. ${ }^{21,22}$ Literature highlights the need for improving the knowledge of dentists with regards 86 to the provision of oral health care to pregnant women. . $^{21,22,23,24,25}$ There have been only a few 87 studies investigating the perception of dentists in Pakistan towards the provision of oral health 88 care to pregnant women. ${ }^{26}$ In light of the observed association of oral disease severity with 89 neonatal mortality ${ }^{3}$, it is important to explore the knowledge, attitudes, and perceptions of 90 Pakistani dentists regarding the oral healthcare of pregnant women. 
91 Therefore, the objectives of this study were to assess the knowledge, attitude, and practice of

92 dentists towards providing oral health care to pregnant women, and to identify barriers and

93 predictors of periodontal and caries related to perinatal oral healthcare practices.

\section{Materials \& Methods}

95 A cross-sectional analytical survey was conducted from May 2018 to October 2018 on the dental

96 practitioners registered with Pakistan Medical Commission and are working in the Islamabad-

97 Rawalpindi metropolitan area, Pakistan by utilizing a convenience sampling technique. The

98 participant information sheets, questionnaires, and consent forms were delivered by mail to 350

99 dentists along with the stamped envelopes for returning the filled questionnaires and consent

100 forms by post. Potential participants were informed that participation was voluntary, and written

101 informed consent was taken from all the participants. The researchers kept all the obtained

102 information confidential. Ethics approval was acquired from Riphah International University's

103 Institutional Review Board (IIDC/IRC/2018/03/07).

104 The validated questionnaire developed by George et al (2017) was used with permission. ${ }^{23}$ The

105 survey questionnaire had four subsections with questions on knowledge, attitude, practices

106 concerning oral healthcare during pregnancy, and barriers perceived for providing oral healthcare

107 to pregnant women. Moreover, demographic details were also acquired. The questionnaire

108 design comprised of multiple-choice items ("true",/False"/“Not sure") in the domain of

109 knowledge and for the assessment of dentists' attitudes, practices, and barriers Likert scales were

110 used.

111 The population prevalence of counseling pregnant patients regarding caries prevention and

112 transmission was unknown. Consequently, 50\% prevalence was presumed for the conservative 
113 estimate. For estimation of the population proportion with the power value of 80 percent, alpha

$114(\alpha)$ of 0.05 , and precision of \pm 0.1 , the sample size of 97 was calculated.

115 Survey data were analyzed by utilizing SPSS version 23 (SPSS, Chicago, IL, USA). Descriptive

116 statistics were utilized for assessing the knowledge, practices, attitudes, and barriers to practicing

117 dentists concerning oral healthcare during pregnancy. The questions' responses in the domain of

118 knowledge were calculated out of 25 after marking the responses to the questions against the

119 systematic reviews ${ }^{27,28}$ and evidence-based guidelines. ${ }^{29,30}$ To explore the knowledgeability, 120 attitudes, practices, and barriers of dentists regarding oral health in pregnancy, descriptive 121 statistical analyses were used.

122 Contingency tables were generated to explore the relationship between different dependent 123 variables of interest. Those variables expressed on the ordinal scale were converted into 124 dichotomous variables. For instance, the items on the practice domain which were originally 125 expressed on a 3 point scale, comprising of "always", "sometimes" and "never" responses, were 126 dichotomized by combining responses of "always" and "sometimes" and leaving "never" as a 127 separate category. Similarly, items for the attitude and barrier domain, which were originally 128 expressed on a 5-point Likert scale were dichotomized by merging responses of "strongly agree" 129 and "agree" as one category and combining the remaining responses as another. Chi-square and 130 Fisher's exact test were used to analyze associations between different categorical (knowledge, 131 attitude, practice, and barrier) variables of interest. Those variables which exhibited a statistically 132 significant association were then selected for running a regression.

133 Binary logistic regression was used to analyze the probability of predicting group membership to 134 the dependent variable using different independent variables determined from contingency 135 tables. Two variables of the practice domain (counseling pregnant women regarding caries 
136 prevention and transmission, counseling regarding the association of poor perinatal periodontal

137 health and negative pregnancy outcomes) and one from the attitude domain (treatment of

138 periodontal disease during pregnancy positively affects pregnancy outcome) were identified as

139 the dependent variables to generate prediction models. While various items from the knowledge

140 domain were identified as independent (predictor) variables. These dependent and independent

141 variables were treated in their dichotomous form and not in their ordinal form. The goodness of

142 fit of the prediction models was determined using the Hosmer and Lemeshow Test, with a P-

143 value of $>0.05$ indicating a good fit of the model compared to the null model. Odds ratios with

$14495 \%$ confidence intervals were calculated for each of the independent (predictor) variables.

\section{Results}

146 Out of 350 dentists, 196 responded. After excluding 43 incomplete questionnaires, a total of 143

147 were selected for final analysis, with a response rate of roughly $41 \%$. The mean age of the

148 respondents was $30.64 \pm 5.1$ years with a mean experience of $6.2 \pm 4.3$ years and about $36.9 \pm 16.7$

149 working hours per week. The majority of the respondents were female (58\%) working in a

150 private setting $(69.2 \%)$ with a bachelor's degree (58.7\%). The average numbers of pregnant

151 patients seen by these dentists were between 1 and 5 (72\%).

152 The mean knowledge score of the respondents was $15.86 \pm 3.34$. The lowest correct responses

153 were noted in the questions pertaining to periodontal health while the most correct answers were

154 related to the use of drugs in pregnant patients (Table 1).

155 The responses to the questions addressing the attitude are shown in Table 2. Most respondents

156 (97.2\%) agreed with the importance of maintaining oral health during pregnancy. About 67

157 (46.9\%) dentists expressed concern for treating pregnant patients without acquiring consent from

158 their general practitioners. 
159 Table 3 details various practice considerations of the respondents. About $37.1 \%$ of the dentists

160 advised pregnant patients to delay the dental visit until after pregnancy. Scaling and polishing

161 (55.9\%) was the most commonly performed procedure by respondents while full mouth

162 radiographs $(71.3 \%)$ were the most avoided procedure. Only $83(58 \%)$ dentists counseled the

163 patients regarding caries prevention and transmission.

164 The concern of pregnant women regarding the safety of dental procedures $(77.6 \%)$ and the lack

165 of concern for oral health during pregnancy (74.1\%) were the most common barriers identified in

166 the provision of perinatal oral health care (Figure 1).

167 The advice to delay dental visits until after pregnancy was 8 times more likely to be observed

168 among dentists who lacked the knowledge of the importance of oral health during pregnancy $(\mathrm{P}=$

$1690.04, \mathrm{OR}=8.75)$. Dentists were more likely to consult obstetricians regarding dental procedures

170 when they fear a risk of labour in the dental practice $(\mathrm{P}<0.05, \mathrm{OR}=3.72)$ or when they feel they

171 have less time for providing advice in practice $(\mathrm{P}<0.05, \mathrm{OR}=3.49)$.

172 The results of binary logistic regression are shown in Table 4. Dentists who had the knowledge

173 of periodontal disease association with preterm delivery were about 4 times more likely to treat

174 periodontal disease during pregnancy in the hope of positively affecting pregnancy outcomes $(\mathrm{P}=$ $1750.013, \mathrm{OR}=3.95)$. Dentists lacking updated knowledge of periodontal disease and its 176 consequences in pregnant women were 2.5 times more likely to not warn the pregnant women 177 about association of periodontal disease with pregnancy $(\mathrm{P}=0.01, \mathrm{OR}=2.56)$. Dentists knowing 178 about the association between maternal oral health and childhood decay were more likely to 179 counsel pregnant patients regarding caries prevention $(\mathrm{P}>0.05, \mathrm{OR}=3.75)$.

180 Discussion

181 As scientific evidence highlighting the importance of perinatal oral health continues to grow, the 
182 provision of oral health care for pregnant women becomes more important. ${ }^{4,5,6}$ This study 183 identified a positive attitude of dentists towards the provision of oral health care to pregnant 184 women with 97.2\% recognizing its importance. A similar attitude was expressed by dentists in 185 other parts of the world as well. ${ }^{23,24}$

186 Despite the development of perinatal oral health guidelines and consensus over the safety of 187 various dental procedures in pregnancy, a hesitation to treat pregnant women continues to persist 188 among dentists. ${ }^{22,31}$ In this study $37.1 \%$ of dentists advised pregnant women to defer dental 189 appointments until after pregnancy which is significantly more than that reported (1.6\%) by 190 Australian dentists. ${ }^{23}$ However, this was less than that reported by Wali et al (47.5\%) while 191 investigating a population of Pakistani dentists. ${ }^{26}$ These differences can be explained by the 192 variable adoption of evidence-based practices by dentists practicing in different regions. The 193 literature has explored various reasons behind this hesitation to treat pregnant women. George et 194 al identified the lack of knowledge of risks associated with the treatment of pregnant women and 195 the concern of treating them without the prior consent of attending general physicians as 196 important predictors for deferring dental appointments. ${ }^{23}$ However, our study highlighted that 197 dentists who did not recognize the importance of perinatal oral health were more likely to delay 198 dental visits of pregnant women.

199 While $42 \%$ of dentists in the present study identified the lack of knowledge of risks associated 200 with treating pregnant women as a barrier in offering treatment to pregnant women, $81.8 \%$ still 201 believed in having the adequate skill to advise pregnant women on oral health. A similar 202 disparity in the confidence to advise pregnant women and the apprehension of treating them was 203 reported in the studies of Vieira et al, George et al and Heubner et al. ${ }^{23,25,33}$ 
204 The knowledge of a majority of the dentists participating in the present study conformed to the 205 current evidence-based practices for perinatal oral health. About $88.8 \%$ of dentists were aware of 206 the safety of basic dental treatments in pregnancy. These findings are comparable to the reports 207 on Turkish and Pakistani dentists. ${ }^{26,32}$ However, dentists from Australia and the United States 208 were overall more knowledgeable regarding the safety of dental procedures in pregnancy. ${ }^{13,16,23}$ 209 In the current study, knowledge regarding the safety of certain procedures like exposing dental 210 radiographs $(31.5 \%)$, dental extractions (49\%), local anesthesia $(51.7 \%)$, and root canal 211 treatment $(67.85 \%)$ was found to be deficient. Similar results were reported in the previous 212 studies. ${ }^{21,22,23,25,26,28}$ Even though dental radiography is not contraindicated in pregnancy ${ }^{27}$, 213 several studies have reported similar misinformation of dentists regarding its safety. $21,22,23,25,26,28$ 214 Most of the dentists $(68.5 \%)$ in the present study believe that dental radiography is unsafe in 215 pregnancy and which explains why only $22.4 \%$ of the dentists agree with the practice of taking 216 periapical radiographs. While the judicious use of dental radiographs during pregnancy is 217 acceptable it is best to avoid unnecessary radiation exposure and to limit such practices to the 218 second trimester. ${ }^{34}$ This can be explained perhaps by the possibility that most dentists might 219 associate safety of dental radiography with $2^{\text {nd }}$ trimester as observed by Heubner et al. ${ }^{25}$ The 220 $43.4 \%$ of the dentists who use periapical radiographs "sometimes" in the present study could 221 have perceived a similar trimester associated safety of dental radiography. This can be 222 counterproductive in establishing an accurate diagnosis and delivering appropriate treatment to 223 pregnant women.

224 Another misinformation is regarding the safety of local anesthetic use in pregnant women as only 225 half of the respondents in the current study correctly regarded them as safe. This is contrary to 226 current evidence wherein lignocaine is safe as a local anesthetic for use in pregnant women. ${ }^{31} \mathrm{~A}$ 
227 similar trend was reported by Ugurlu et al while George et al reported a much higher percentage

228 of dentists recognizing the safety of local anesthetics in pregnancy. ${ }^{23,28}$ The safety of most 229 commonly prescribed drugs was acknowledged by the majority of the dentists in our study which 230 is encouraging as inappropriate use of drugs can have detrimental effects on perinatal health. 231 Surprisingly though the safest drug on the list was amoxicillin and it was identified as safe by 232 relatively fewer respondents. ${ }^{35}$ This can be alarming as Amoxicillin is the first choice of 233 antibiotics for the management of pregnant patients reporting facial swelling. ${ }^{36}$

234 Perhaps the most severe deficiencies in knowledge were present with respect to the association 235 of the periodontal disease with various pregnancy complications. The same was observed among 236 dentists of other nationalities as well. ${ }^{23,25,28}$ Despite the mixed evidence of an association 237 between perinatal periodontal health and obstetric complications in literature, a positive 238 association has been recognized in economically disadvantaged societies. ${ }^{3,37,38}$ Therefore, in 239 Pakistan it becomes more important for dentists to accept the importance of this association and 240 counsel pregnant women accordingly. It was encouraging to see that dentists who regarded this 241 association as weak were even more likely to advise pregnant women regarding the said 242 association $(\mathrm{P}<0.05, \mathrm{OR}=2.56)$. Perhaps the knowledge of preterm birth association with poor 243 periodontal health was encouraging them to have a positive counseling attitude $(\mathrm{P}=0.001, \mathrm{OR}=$ 244 3.953). Unlike a periodontal disease, the evidence of perinatal oral health as a risk factor for 245 early childhood caries is more established. ${ }^{39}$ Dentists who knew of the association between poor 246 maternal oral health and early childhood caries were more likely to counsel regarding prevention 247 and transmission $(\mathrm{P}>0.05, \mathrm{OR}=3.49)$. However, this disparity between knowledge and practice 248 should be further evaluated due to a lack of statistical significance $(\mathrm{P}=0.20)$. Additionally, those 249 who considered this association weak were less likely to counsel pregnant patients $(\mathrm{P}>0.05$, 
$250 \mathrm{OR}=0.198)$. The lack of practice guidelines on perinatal oral health care in Pakistan was 251 identified as a barrier in the provision of counseling regarding periodontal health $(\mathrm{P}>0.05, \mathrm{OR}=$ $2520.470)$ and caries prevention $(\mathrm{P}>0.05, \mathrm{OR}=0.816)$.

253 The results of the present study should be carefully interpreted as there are a few limitations. To 254 begin with, the response rate was low probably due to a large number of items in the surveying 255 instrument. Most experienced dentists have busy routines and might be reluctant to complete 256 long surveys, hence explaining the relatively young age of the respondents in the study. 257 However, this would result in underreporting of correct knowledge and practice parameters as 258 seen in the present study. Another limitation was the absence of trimester-based distinction in the 259 knowledge and practice questions. This resulted in perhaps many respondents selecting the 260 option "sometimes" while answering practice-related questions. Lastly, the research was 261 conducted in one metropolitan area (Rawalpindi-Islamabad) of Pakistan, therefore a cautious 262 approach is recommended while generalizing the findings of the research. Moreover, a future 263 multicenter/multicity study is recommended.

\section{Conclusions}

265 Collectively, the results of our study indicate few gaps in knowledge among some dentists and a 266 need to improve existing attitudes towards perinatal oral health. Moreover, there is a need to 267 address issues like the development of practice guidelines for perinatal oral health care in 268 Pakistan. Dentists failing to recognize the importance of perinatal oral health are more likely to 269 be hesitant in treating pregnant patients. Failing to recognize the link between periodontal 270 disease and obstetric complications increases the possibility of hesitance to counsel pregnant 271 patients regarding the same. The appreciation of the evidence for poor perinatal oral health and 
272 risk of early childhood caries increases the likelihood of counseling by dentists on caries 273 prevention.

274 Acknowledgements

275 The authors would like to thank Dr. Ajesh George, University of Western Sydney, for 276 permission to use his questionnaire

\section{Funding:}

278 Researchers would like to thank the Deanship of Scientific Research, Qassim University for 279 funding the publication of this project

280

281

282

283

284

285

286

287

288

289

290

291

292

293

294

295

\section{References}

1. Riaz A, Javed MQ, Chaudhary FA, Khan AK. Knowledge, Attitude, and Practices of pregnant women regarding oral health at Railway Hospital Rawalpindi, Pakistan. Pakistan J. Medical Health Sci.2020; 14(3):738-743

2. Krüger MS, Lang CA, Almeida LH, Bello-Corrêa FO, Romano AR, Pappen FG. Dental pain and associated factors among pregnant women: an observational study. Matern Child Health J. 2015;19(2): 504-510.

3. Mobeen N, Jehan I, Banjay N, J Moore, EM McClure, O Pasha, et al. Periodontal disease and adverse birth outcomes: a study from Pakistan. Am J Obstet Gynecol. 2008;198(5):514 e1-e8.

4. Vergnes JN, Sixou M. Preterm low birth weight and maternal periodontal status: a metaanalysis. Am J Obstet Gynecol. 2007;196(2):135.e1-7.

5. Wazir SS, Arora P, Ghosh S, Bhagat V, Khurana S, Mahanta S. Influence of maternal periodontal health as a risk factor for low-birth-weight infants in Terai population of Nepal. J Educ Health Promot. 2019;8:233. 
296 6. Loesche WJ. Association of the oral flora with important medical diseases. Curr Opin 297 Periodontol. 1997;4:21-8.

298 7. Qureshi A, Ijaz S, Syed A, Qureshi A, Khan AA. Periodontal infection: a potential risk 299 factor for pre-term delivery of low birth weight (PLBW) babies. J Pak Med Assoc. 2005;55(10):448-52.

301

302

8. da Silva Castro CR, de Sousa Cabral MBB, Mota ELA, Cangussu MCT, Vianna MIP. Analysis of the influence of low birth weight on the time of eruption of dental caries in children in early childhood. J Public Health Dent. 2019;79(4):292-97.

304

9. WHO (2012) Born Too Soon: The Global Action Report on Preterm Birth. Available at: 305 http://www.who.int/pmnch/media/news/2012/preterm_birth_report/en/index3.html

306 (Accessed: 26 July 2017).

307

10. Gupta S, Jain A, Mohan S, Bhaskar N, Walia PK. Comparative evaluation of oral health 308 knowledge, practices and attitude of pregnant and non-pregnant women, and their 309 awareness regarding adverse pregnancy outcomes. Journal of clinical and diagnostic research: JCDR. 2015;9(11):26-32. 
311 11. Scannapieco FA, Bush RB, Paju S. Periodontal disease as a risk factor for adverse pregnancy outcomes. A systematic review. Annals of Periodontology. 2003 ;8(1):70-8. 
313

314

315

316

317

318

319

320

321

322

323

324

325

326

327

328

329

330

331

332

333

334

12. Boggess KA, Edelstein BL. Oral health in women during preconception and pregnancy: implications for birth outcomes and infant oral health. Maternal and child health journal. 2006;10(1):169-74.

13. Bokhari SA, Khan AA. The Relationship of Periodontal Disease to Cardiovascular disease-Review of Literature. JOURNAL-PAKISTAN MEDICAL ASSOCIATION. 2006;56(4):177.

14. Boggess KA, Urlaub DM, Moos MK, Polinkovsky M, El-Khorazaty J, Lorenz C. Knowledge and beliefs regarding oral health among pregnant women. The Journal of the American Dental Association. 2011;142(11):1275-82.

15. Meyer K, Geurtsen W, Günay H. An early oral health care program starting during pregnancy. Clinical oral investigations. 2010;14(3):257-64.

16. George A, Johnson M, Duff M, Blinkhorn A, Ajwani S, Bhole S, Ellis S. Maintaining oral health during pregnancy: perceptions of midwives in Southwest Sydney. Collegian. 2011;18(2):71-9.

17. Duff M, Dahlen HG, Burns E, Priddis H, Schmied V, George A. Designing an oral health module for the Bachelor of Midwifery program at an Australian University. Nurse education in practice. 2017;23:76-81.

18. Proença MA, Franco MM, Rodrigues VP, Costa JF, Costa EL. Association between early childhood caries and maternal caries status: A cross-section study in São Luís, Maranhão, Brazil. European journal of dentistry. 2015 Jan;9(01):122-6.

19. Finlayson TL, Gupta A, Ramos-Gomez FJ. Prenatal Maternal Factors, Intergenerational Transmission of Disease, and Child Oral Health Outcomes. Dent Clin North Am. $2017 ; 61(3): 483-518$.

20. Geisinger ML, Alexander DC, Dragan IF, Mitchell SC. Dental Team's Role in Maternal and Child Oral Health During and After Pregnancy. Compend Contin Educ Dent. 2019;40(2):90-96.

Peer) reviewing PDF | (2021:01:57360:1:0:NEW 15 Jul 2021) 
339 21. Vieira DR, de Oliveira AE, Lopes FF, Lopes e Maia Mde F. Dentists' knowledge of oral 340 health during pregnancy: a review of the last 10 years' publications. Community Dent $341 \quad$ Health. 2015;32(2):77-82.

342 22. Lee RS, Milgrom P, Huebner CE, Conrad DA. Dentists' perceptions of barriers to 343 providing dental care to pregnant women. Womens Health Issues. 2010;20(5):359-65.

344 23. George A, Ajwani S, Bhole S, Dahlen HG, Reath J, Korda A, et al. Knowledge, attitude 345 and practises of dentists towards oral health care during pregnancy: A cross sectional 346 survey in New South Wales, Australia. Aust Dent J. 2017;62(3):301-10.

347 24. Mayberry ME, Norrix E, Farrell C. MDA Dentists and Pregnant Patients: A Survey of $348 \quad$ Attitudes and Practice. J Mich Dent Assoc. 2017;99(1):54-62.

349 25. Huebner CE, Milgrom P, Conrad D, Lee RS. Providing dental care to pregnant patients: a 350 survey of Oregon general dentists. J Am Dent Assoc. 2009;140(2):211-22.

351 26. Wali A, Siddiqui TM, Sarwar A, Anjum A, Rao H. Perception and understanding of 352 dental practitioners in provision of dental treatment to pregnant women in Karachi, 353 Pakistan. Indian J Dent Sci 2016;8:199-204.

354 27. Ide M, Papapanou PN. Epidemiology of association between maternal periodontal 355 disease and adverse pregnancy outcomes- systematic review. J Clin Periodontol. $356 \quad 2013 ; 40($ S14):S181-94.

357 28. Leong PM, Gussy MG, Barrow SY, de Silva-Sanigorski A, Waters E. A systematic 358 review of risk factors during first year of life for early childhood caries. Int J Paed Dent. 359 $2013 ; 23: 235-50$. 
360

361

362

363

364

365

366

367

368

369

370

371

372

373

374

375

376

377

378

379

380

381

382

29. California Dental Association Foundation; American College of Obstetricians and Gynecologists, District IX. Oral health during pregnancy and early childhood: Evidencebased guidelines for health professionals. J Calif Dent Assoc. 2010. 38(6):391-403.

30. American Academy of Pediatric Dentistry. Guideline on perinatal oral health care. Clinical Guidelines Reference Manual. 2011;35:131-136.

31. Steinberg BJ, Hilton IV, Iida H, Samelson R. Oral health and dental care during pregnancy. Dent Clin North Am. 2013;57(2):195-210.

32. Ugurlu M, Orhan H. Knowledge, Attitude and Practices of Dentists about Oral Health Care during Pregnancy: A Cross-sectional Study from Turkey. Journal of Clinical and Diagnostic Research. 2019;13(4):8-11.

33. Da Costa EP, Lee JY, Rozier RG, Zeldin L. Dental care for pregnant women: An assessment of North Carolina general dentists. J Am Dent Assoc. 2010;141(8):986-94.

34. Yenen Z, Ataçağ T. Oral care in pregnancy. J Turk Ger Gynecol Assoc. 2019;20(4):26468.

35. Naseem M, Khurshid Z, Khan HA, Niazi F, Zohaib S, Zafar MS. Oral health challenges in pregnant women: Recommendations for dental care professionals. The Saudi Journal for Dental Research. 2016;7(2):138-46.

36. Ouanounou A, Haas DA. Drug therapy during pregnancy: implications for dental practice. Br Dent J. 2016;220(8):413-17.

37. Han YW. Oral health and adverse pregnancy outcomes-What's next? J Dent Res 2011;90(3):289-293.

38. Offenbacher S, Boggess KA, Murtha AP, et al. Progressive periodontal disease and risk of very preterm delivery. Obstet Gynecol 2006;107(1):29-36. 
383 39. Xiao J, Alkhers N, Kopycka-Kedzierawski DT, Billings RJ, Wu TT, Castillo DA, et al.

384 Prenatal Oral Health Care and Early Childhood Caries Prevention: A Systematic Review 385 and Meta-Analysis. Caries Res. 2019;53(4):411-21.

386

387

388 
Figure 1

\section{Description of barriers to perinatal oral health care provision for dentists}

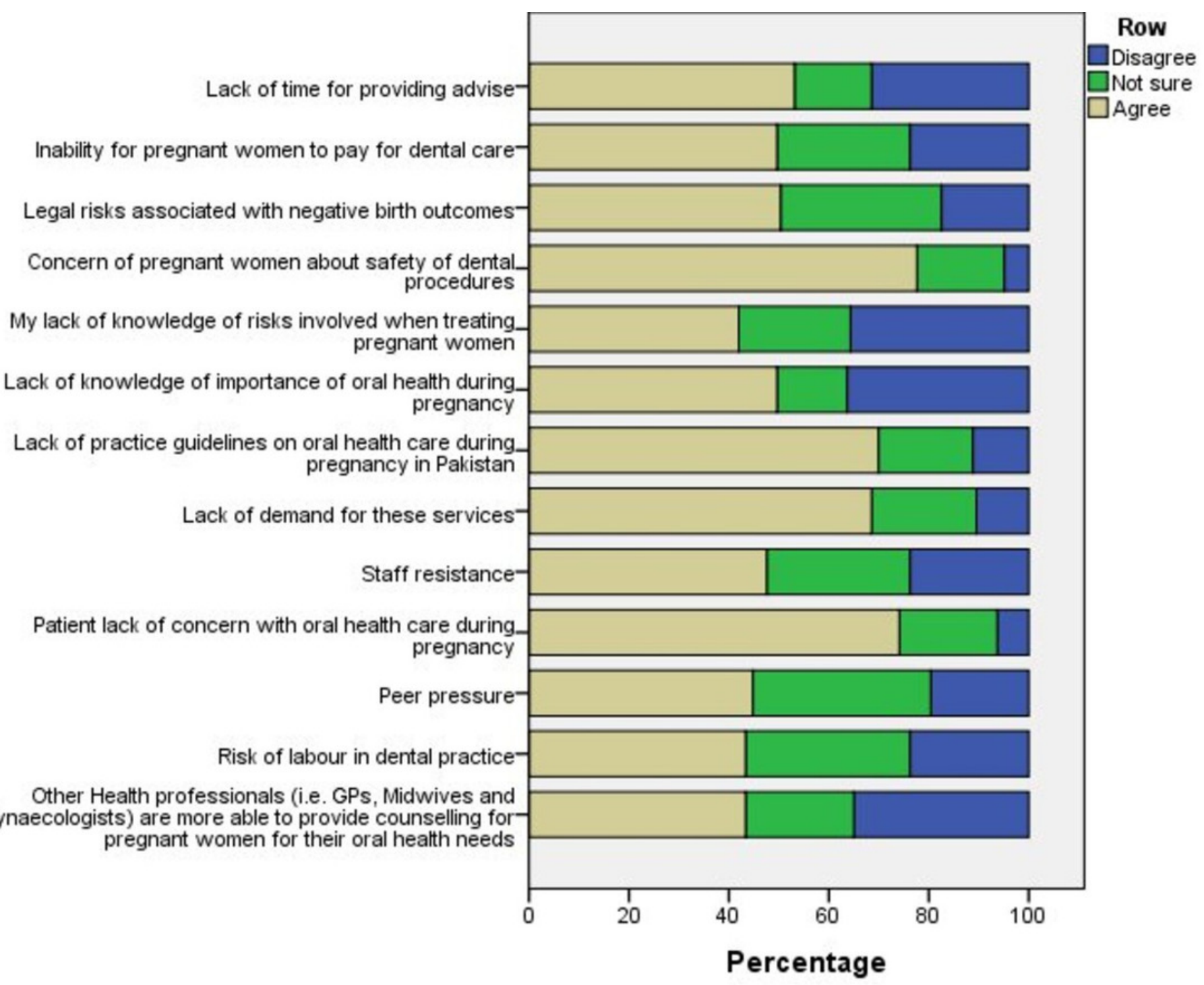




\section{Table 1 (on next page)}

Percentage of correct responses to perinatal oral health knowledge items $(N=143)$ of dentists 


\begin{tabular}{|c|c|}
\hline $\begin{array}{l}\text { Item (correct response as per current evidence } \\
\text { and guidelines) }\end{array}$ & $\begin{array}{l}\text { Correct } \\
\text { Response N (\%) }\end{array}$ \\
\hline $\begin{array}{l}\text { Pregnancy exacerbates existing dental problems } \\
\text { (true) }\end{array}$ & $119(83.2)$ \\
\hline Gingivitis is more serious than periodontitis (false) & $116(81.1)$ \\
\hline $\begin{array}{l}\text { Calcium will be drawn out of mother's teeth by } \\
\text { developing baby (false) }\end{array}$ & $116(81.1)$ \\
\hline $\begin{array}{l}\text { Gingivitis is a potentially reversible infection of } \\
\text { the gums (true) }\end{array}$ & $132(92.3)$ \\
\hline $\begin{array}{l}\text { Poor maternal oral health can contribute to early } \\
\text { childhood decay (true) }\end{array}$ & $58(40.6)$ \\
\hline \multicolumn{2}{|c|}{ Periodontal disease has been associated with the following: } \\
\hline Stillbirth (true) & $24(16.8)$ \\
\hline Preterm delivery (true) & $51(35.7)$ \\
\hline Spontaneous abortion/miscarriage (true) & $39(27.3)$ \\
\hline Preeclampsia (true) & $30(21)$ \\
\hline Low birth weight (true) & $62(43.4)$ \\
\hline $\begin{array}{l}\text { Women should receive preventive dental care } \\
\text { during pregnancy (true) }\end{array}$ & $113(79)$ \\
\hline $\begin{array}{l}\text { Basic dental treatment is safe during pregnancy } \\
\text { (true) }\end{array}$ & $127(88.8)$ \\
\hline $\begin{array}{l}\text { It is unsafe to obtain dental radiographs in pregnant } \\
\text { women (false) }\end{array}$ & $45(31.5)$ \\
\hline $\begin{array}{l}\text { Pregnant women should receive only emergency } \\
\text { dental care (false) }\end{array}$ & $35(24.5)$ \\
\hline $\begin{array}{l}\text { Elective dental treatment should be delayed until } \\
\text { after pregnancy (true) }\end{array}$ & $106(74.1)$ \\
\hline \multicolumn{2}{|l|}{ These dental procedures are safe during pregnancy: } \\
\hline Extractions (true) & $70(49)$ \\
\hline Local anaesthetic (true) & $74(51.7)$ \\
\hline Root canal Treatment (true) & $97(67.8)$ \\
\hline Scaling and root planning (true) & $116(81.1)$ \\
\hline \multicolumn{2}{|l|}{ These medications are safe during pregnancy: } \\
\hline Paracetamol (true) & $132(92.3)$ \\
\hline Aspirin (false) & $128(89.5)$ \\
\hline NSAIDs (false) & $119(83.2)$ \\
\hline Amoxicillin (true) & $104(72.7)$ \\
\hline Erythromycin (false) & $120(83.9)$ \\
\hline Doxycycline (false) & $135(94.4)$ \\
\hline
\end{tabular}

2

3

4 
Table 2 (on next page)

Responses for perinatal oral healthcare related attitude items $(\mathrm{N}=143)$. 


\begin{tabular}{|l|l|l|l|}
\hline Attitude & Agree N(\%) & Not Sure N(\%) & Disagree N(\%) \\
\hline Maintaining oral health during pregnancy is important & $139(97.2)$ & $3(2.1)$ & $1(0.7)$ \\
\hline Pregnant women should receive a dental check early in their pregnancy & $138(96.5)$ & $4(2.8)$ & $1(0.7)$ \\
\hline $\begin{array}{l}\text { Treatment of periodontal disease during pregnancy positively affects } \\
\text { pregnancy outcome }\end{array}$ & $78(54.5)$ & $48(33.6)$ & $17(11.9)$ \\
\hline $\begin{array}{l}\text { Pregnant women are more likely to seek dental care if their antenatal care } \\
\text { providers recommend it }\end{array}$ & $112(78.3)$ & $28(19.6)$ & $3(2.1)$ \\
\hline $\begin{array}{l}\text { Antenatal care providers are better able than dentists to counsel pregnant } \\
\text { women about oral health }\end{array}$ & $70(49)$ & $28(19.6)$ & $45(31.5)$ \\
\hline $\begin{array}{l}\text { I am concerned about providing treatment to pregnant women without } \\
\text { consent from their GPs }\end{array}$ & $67(46.9)$ & $19(13.3)$ & $57(39.9)$ \\
\hline $\begin{array}{l}\text { Currently there is good understanding between ANC providers and dentists } \\
\text { regarding dental care for pregnant women }\end{array}$ & $44(30.8)$ & $36(25.2)$ & $63(44.1)$ \\
\hline My practice is too busy to provide oral health advice for pregnant women & $30(21)$ & $12(8.4)$ & $101(70.6)$ \\
\hline $\begin{array}{l}\text { There is insufficient time to advise pregnant women on oral health during a } \\
\text { dental visit }\end{array}$ & $42(29.4)$ & $24(16.8)$ & $77(53.8)$ \\
\hline I have the skills to advise pregnant women on oral health & $117(81.8)$ & $21(14.7)$ & $5(3.5)$ \\
\hline The cost of dental treatment is a barrier to advising pregnant women & $61(42.7)$ & $33(23.1)$ & $49(34.3)$ \\
\hline There is little I can do to affect a pregnant woman's oral hygiene & $42(29.4)$ & $18(12.6)$ & $83(58)$ \\
\hline $\begin{array}{l}\text { The link between periodontal disease and preterm birth is too tenuous for me } \\
\text { to warn pregnant women about it }\end{array}$ & $65(45.5)$ & $47(32.9)$ & $31(21.7)$ \\
\hline $\begin{array}{l}\text { The link between dental caries in mothers and in babies is too tenuous for me } \\
\text { to warn my patients about it }\end{array}$ & $56(39.2)$ & $42(29.4)$ & $45(31.5)$ \\
\hline I am interested in further information about dental care to pregnant women & $132(92.3)$ & $5(3.5)$ & $6(4.2)$ \\
\hline $\begin{array}{l}\text { I am interested in further training to provide dental assessments to pregnant } \\
\text { women }\end{array}$ & $125(87.4$ & $13(9.1)$ & $5(3.5)$ \\
\hline $\begin{array}{l}\text { There is a need for universal guidelines for oral health care during pregnancy } \\
\text { for all health professionals }\end{array}$ & $130(90.9)$ & $8(5.6)$ & $5(3.5)$ \\
\hline
\end{tabular}




\section{Table $\mathbf{3}$ (on next page)}

Responses for perinatal oral healthcare related practices of dentists $(\mathrm{N}=143$ ) 


\begin{tabular}{|l|l|l|l|}
\hline Practices & Always N(\%) & $\begin{array}{l}\text { Sometimes N } \\
(\mathbf{\%})\end{array}$ & Never N(\%) \\
\hline $\begin{array}{l}\text { I discuss the importance of oral health with pregnant women } \\
\text { during clinical care }\end{array}$ & $94(65.7)$ & $48(33.6)$ & $1(0.7)$ \\
\hline $\begin{array}{l}\text { I advise pregnant women to delay dental visits until after } \\
\text { pregnancy }\end{array}$ & $53(37.1)$ & $81(56.6)$ & $9(6.3)$ \\
\hline $\begin{array}{l}\text { I advise pregnant women to visit dentists during early } \\
\text { pregnancy }\end{array}$ & $83(58)$ & $50(35)$ & $10(7)$ \\
\hline $\begin{array}{l}\text { I provide counselling regarding the association of poor } \\
\text { periodontal health with negative birth outcomes }\end{array}$ & $63(44.1)$ & $49(34.3)$ & $31(21.7)$ \\
\hline $\begin{array}{l}\text { I provide counselling regarding caries prevention and } \\
\text { transmission }\end{array}$ & $83(58)$ & $49(34.3)$ & $11(7.7)$ \\
\hline I consult obstetricians before/after dental procedures & $39(27.3)$ & $73(51)$ & $31(21.7)$ \\
\hline Types of dental treatment I advise to receive during pregnancy: & $119(83.2)$ & $22(15.4)$ & $2(1.4)$ \\
\hline Routine examination & $110(76.9)$ & $31(21.7)$ & $2(1.4)$ \\
\hline Routine cleaning & $83(58)$ & $44(30.8)$ & $16(11.2)$ \\
\hline Periodontal (gum) treatment & $74(51.7)$ & $51(35.7)$ & $18(12.6)$ \\
\hline Fillings/crowns & & & \\
\hline Routine treatments I undertake: & $80(55.9)$ & $42(29.4)$ & $21(14.7)$ \\
\hline Scaling and root planning & $32(22.4)$ & $62(43.4)$ & $49(34.3)$ \\
\hline Radiographs, single periapical & $10(7)$ & $31(21.7)$ & $102(71.3)$ \\
\hline Full mouth radiographs & $38(26.6)$ & $74(51.7)$ & $31(21.7)$ \\
\hline Single tooth extraction & $45(31.5)$ & $83(58)$ & $15(10.5)$ \\
\hline Endodontic/root canal treatment therapy & $39(27.3)$ & $80(55.9)$ & $24(16.8)$ \\
\hline Administrating local anaesthetic & $12(8.4)$ & $28(19.6)$ & $103(72)$ \\
\hline Providing nitrous oxide & $12(8.4)$ & $36(25.2)$ & $95(66.4)$ \\
\hline Extracting tooth impactions & $74(51.7)$ & $59(41.3)$ & $10(7)$ \\
\hline Opening and broaching to relieve pain & $67(46.9)$ & $69(48.3)$ & $7(4.9)$ \\
\hline Incising and draining an abscess & $68(47.6)$ & $69(48.3)$ & $6(4.2)$ \\
\hline Placing a temporary restoration & $31(21.7)$ & $84(58.7)$ & $28(19.6)$ \\
\hline Antibiotics & \multicolumn{2}{|l}{} \\
\hline
\end{tabular}

3

4

5

6 
Table 4 (on next page)

Association of predictor variables with practice and attitude variables ( $N=143)$ 
1

2

\begin{tabular}{|c|c|c|}
\hline Practice or Attitude Variable & Predictor Variables & Odds Ratio (95\% CI) \\
\hline \multirow{3}{*}{$\begin{array}{l}{ }^{1} \text { Practice of counselling pregnant } \\
\text { patients regarding caries } \\
\text { prevention and transmission }\end{array}$} & Poor maternal oral health can contribute to early childhood decay & $3.749(0.756-18.580)$ \\
\hline & $\begin{array}{l}\text { The link between dental caries in mothers and in babies is too tenuous for } \\
\text { me to warn my patients about it }\end{array}$ & $0.198(0.024-1.644)$ \\
\hline & $\begin{array}{l}\text { Lack of practice guidelines on oral health care during pregnancy in } \\
\text { Pakistan }\end{array}$ & $0.816(0.221-3.022)$ \\
\hline \multirow{6}{*}{$\begin{array}{l}{ }^{2} \text { Practice of counselling pregnant } \\
\text { women regarding association of } \\
\text { poor periodontal health with } \\
\text { negative birth outcomes }\end{array}$} & $\begin{array}{l}\text { Periodontal disease has been associated with the Spontaneous Abortion/ } \\
\text { Miscarriage }\end{array}$ & $1.551(0.481-5.00)$ \\
\hline & Periodontal disease has been associated with the Still Birth & $0.931(0.242-3.57)$ \\
\hline & Periodontal disease has been associated with the preeclampsia & $1.052(0.319-3.475)$ \\
\hline & $\begin{array}{l}\text { The link between periodontal disease and preterm birth is too tenuous for } \\
\text { me to warn pregnant women about it }\end{array}$ & $2.561(1.04-6.307) *$ \\
\hline & Maintaining oral health during pregnancy is important & $1.679(0.149-18.938)$ \\
\hline & $\begin{array}{l}\text { Lack of practice guidelines on oral health care during pregnancy in } \\
\text { Pakistan }\end{array}$ & $0.470(0.171-1.294)$ \\
\hline \multirow{3}{*}{$\begin{array}{l}{ }^{3} \text { Attitude variable "treatment of } \\
\text { periodontal disease during } \\
\text { pregnancy positively affects } \\
\text { pregnancy outcome" }\end{array}$} & Periodontal disease has been associated with the Preterm Delivery & $3.953(1.61-9.69) *$ \\
\hline & $\begin{array}{l}\text { Periodontal disease has been associated with the Spontaneous } \\
\text { Abortion/Miscarriage }\end{array}$ & $0.791(0.28-2.22)$ \\
\hline & Periodontal disease has been associated with the Low birth weight & $1.770(0.70-4.42)$ \\
\hline
\end{tabular}

$3 \quad{ }^{1}$ Negelkerke R square $=0.120$, $($ Hosmer and Lemeshow Test, $\mathrm{P}=0.776)$

$4 \quad{ }^{2}$ Negelkerke R square $=0.087$, (Hosmer and Lemeshow Test, $\left.\mathrm{P}=0.889\right),{ }^{*} \mathrm{P}<0.05$

$5 \quad{ }^{3}$ Negelkerke R square $=0.234$, (Hosmer and Lemeshow Test, $\left.\mathrm{P}=0.24\right),{ }^{*} \mathrm{P}<0.05$

6

7

8

9

10

11

12 